\title{
Effect of effective microorganisms on wheat growth under salt stress condition
}

\author{
Hassan Abu-Qaoud ${ }^{1}$, Heba Al-Fares ${ }^{1 *}$, Munqez J.Y. Shtaya ${ }^{1}$, and Nuha Shawarb ${ }^{2}$ \\ ${ }^{1}$ An-Najah National University, Faculty of Agriculture and Veterinary Medicine, Nablus P.O. Box 707, Palestine. \\ *Corresponding author (heba-alfares@najah.edu). \\ ${ }^{2}$ An-Najah National University, Faculty of Science, Nabus P.O. Box 707, Palestine.
}

Received: 8 January 2021; Accepted: 17 March 2021; doi:10.4067/S0718-58392021000300351

\begin{abstract}
Effective microorganisms (EM) are important beneficial fungi and bacteria mixed culture that is used as an inoculant to improve soil quality and health, enhance plant growth, yield, and quality. This study was conducted to evaluate the effect of inoculating various concentration of $\operatorname{EM}\left(50,100\right.$ and $\left.200 \mathrm{~mL} \mathrm{~L}^{-1}\right)$ on growth of wheat (Triticum aestivum L.) seedlings, grown under $\mathrm{NaCl}$ regime $\left(6 \mathrm{dS} \mathrm{m}^{-1}\right)$, including fresh and dry weight, chlorophyll content, maximum fluorescence yield $\left(\mathrm{F}_{\mathrm{m}}\right)$, variable fluorescence yield $\left(\mathrm{F}_{\mathrm{v}}\right)$, optimum photosystem II (PSII) quantum yield $(\mathrm{QY})$ and ratio of fluorescence decline in steady state (RFD). Seedlings subjected to salt treatment exhibited significantly $60 \%$ and $30 \%$ reduction in both fresh in dry weight; respectively, however, when seedlings under saline condition were treated with EM at both 50 and $100 \mathrm{~mL}^{-1}$, fresh weight was increased two folds. However, for both dry weight and plant length, EM at $100 \mathrm{~mL}^{-1}$ showed the highest significant values compared to salt treated seedlings ( $40 \%$ and $18 \%$, respectively). Salinity treatment reduced significantly chlorophyll content, $\mathrm{F}_{\mathrm{v}} / \mathrm{F}_{\mathrm{m}}$ and QY, however, the addition of $\mathrm{EM}$ at $200 \mathrm{~mL} \mathrm{~L}^{-1}$ alleviated the effect of salt stress on photosynthetic parameters. The application of both 100 and $200 \mathrm{~mL} \mathrm{~L}^{-1}$ alleviated the salt effect resulted in a similar chlorophylls content as the control (36.23 and 34.12 SPAD units) respectively. EM application at $200 \mathrm{~mL} \mathrm{~L}^{-1}$ significantly lowered electrical conductivity from 14.35 to $10.29 \mathrm{dS} \mathrm{m}^{-1}$ of the media. In conclusion, EM can be used to counter act salt effect in soil and improve growth behavior of wheat plants under salinity conditions.
\end{abstract}

Key word: Effective microorganisms, salinity, Triticum aestivum.

\section{INTRODUCTION}

Salinity is considered as one of the important abiotic stresses that affect plant growth. Nearly, more than $6 \%$ of the total cultivated land of the world is suffering from salinity mainly in arid and semi-arid regions (Bui, 2013). About 20\% of irrigated land and 2\% of rainfed agricultural land in the world is suffering from salinity (Singh and Jha, 2016). Nutrient uptake and plant growth are reduced by the accumulation of salt in the soil solution (Singh and Jha, 2016), plants growing in saline conditions undergo osmotic stress due to the rise in the concentration of $\mathrm{Na}^{+}$and $\mathrm{Cl}^{-}$, which leads to ionic imbalance in plant tissue and resulting in reduction of the uptake of nutrients (Hasegawa et al., 2000). Plant tolerance to different abiotic stresses including salinity is highly linked to antioxidant enzymes. Antioxidant enzymes and nonenzymatic antioxidants produced by plant cells protect plants against salinity stresses (Upadhyay and Singh, 2015).

Salt tolerance depends mainly on the ability of roots to uptake $\mathrm{Na}^{+}$and $\mathrm{Cl}^{-}$, either restricted or controlled uptake, and continue uptake essential nutrients, mainly $\mathrm{K}^{+}$and $\mathrm{NO}_{3}{ }^{-}$. As a consequence, the favorable uptake of $\mathrm{K}^{+}$over $\mathrm{Na}^{+}$ is considered as an important issue related to salinity tolerance in various halophytes and non-halophytes (Ashraf et al., 2004). 
Several mechanisms are used to alleviate or control the influence of salt stress on plants and one of them is using salttolerant root-colonizing bacterial inoculants (Egamberdieva and Kucharova, 2009). Soil microorganisms have beneficial effect on increasing fertility and crop yield (Long et al., 2014; Xu et al., 2016; Sun et al., 2017; Mtolera and Dongli, 2018) for instance, microorganisms such as Pseudomonas, Azotobacter, Azospirillum and arbuscular mycorrhizal fungi are able to release growth promoting factor, i.e., gibberellins and auxins that play an important role in reducing salt stress in host plants (Evelin et al., 2009). Growth promoting activities of microorganisms has been reported during salinity stress of several plants including wheat (Kaushal and Wani, 2016). Upadhyay and Singh (2015) reported increase in dry weight, total soluble solids and proline content in wheat inoculated with plant growth promoting rhizobacteria (PGPR) strains, and grown under different salinity levels. Bui (2013) reported that growth and yield attributes were improved in wheat grown under different salinity levels and inoculated with multi-strain of growth promoting bacteria. The ability of these microorganisms to increase nutrient absorption, developing plant root system and controlling plant pathogens, lead to its widespread use and it is expected that in the future they can replace a portion of chemical fertilizers (Kaushal and Wani, 2016; Safari et al., 2016).

Effective microorganisms (EM) are important beneficial microorganisms mixed cultures used as inoculant to increase microbial diversity of soil and water (Mtolera and Dongli, 2018). This usually can improve soil quality and health, which will enhance plant growth, yield, and quality. Wheat (Triticum aestivum L.) is the main cereal crop cultivated under rainfed conditions in Palestine. Soil salinity is one of the major restrictions of wheat cultivation; therefore, the objective of this study was to evaluate the potential use of $\mathrm{EM}$ for improving growth of wheat under $\mathrm{NaCl}$ stress conditions.

\section{MATERIALS AND METHODS}

\section{Plant and soil preparation}

Wheat (Triticum aestivum L.) seeds of the local var. Dubbie were surface sterilized with $70 \%$ alcohol and then seeded in sterilized plastic petri dishes $(9 \mathrm{~cm}$ diameter) with filter paper, seeds were watered with distilled water until started germination. Germinated seeds were then carefully transferred to sterilized plastic pots $(10 \times 10 \times 15 \mathrm{~cm})$ containing heat-sterilized sandy loam soil with the following properties: $\mathrm{pH} 7.55$, electrical conductivity (EC) $1.78 \mathrm{dS} \mathrm{m}^{-1}, 2.724 \%$ organic matter, $0.29 \%$ total N, $260 \mathrm{mg} \mathrm{Ca}, 120 \mathrm{ppm} \mathrm{Mg}, 16 \mathrm{ppm} \mathrm{Na}, 60 \mathrm{ppm} \mathrm{K}, 244$ ppm P. Four seedlings were planted in each pot. The experiment was conducted under controlled conditions in a growth chamber at $22^{\circ} \mathrm{C}$ day/night temperatures and 12:12 h light/dark cycle (light intensity was $350 \mu \mathrm{mol} \mathrm{m}^{-2} \mathrm{~s}^{-1}$ ). Plants were manually irrigated with distilled water as required for $7 \mathrm{~d}$. After that, plants were irrigated with a solution of $\mathrm{NaCl}$ at $6 \mathrm{dS} \mathrm{m}^{-1}$. Control plants were irrigated with distilled water.

\section{Effective microorganisms application}

Effective microorganisms (EM) culture was a mixed culture of beneficial microorganisms, primarily photosynthetic and lactic acid bacteria, and yeast (EM.1, TeraGanix, South Alto, Texas, USA), the culture (EM.1) was activated by using 1 part EM, 1 molasses and 20 distilled water, the culture was kept in a growth chamber at $25^{\circ} \mathrm{C}$ for fermentation. After 2 $\mathrm{wk}$, the activated culture was ready to be used, three levels of the diluted stock were applied $\left(50,100\right.$, and $\left.200 \mathrm{~mL} \mathrm{~L}^{-1}\right)$. Two milliliters of each concentration of EM were added to six pots, distilled water was added to the control treatment, and $\mathrm{NaCl}$ treatment received only $\mathrm{NaCl}$ solution (Table 1). The experiment was arranged in complete randomized design with six replicates.

\section{Measurement and data analysis}

Data were collected 3 wk after application. Chlorophyll content in plant samples was measured by chlorophyll meter (SPAD502, Konica Minolta Optics, Osaka, Japan). Photosynthesis was also measured using the FS-FI-2200 FluorCam System (PSI [Photon Systems Instruments], Drasov, Czech Republic). Before transporting the plants to the FluorCam System, the last fully expanded leaf of each plant was placed in a horizontal position and it was installed by metal staples. Immediately, the plants were transferred to the FluorCam system, measurements were collected every $2 \mathrm{~h}$ for $3 \mathrm{~d}$, photochemistry were driven by blue $450 \mathrm{~nm}$ actinic light $\left(200 \mathrm{mE} \mathrm{m}^{-2} \mathrm{~s}^{-1}\right)$, data obtained for the analysis included: maximum fluorescence yield $\left(\mathrm{F}_{\mathrm{m}}\right)$, variable fluorescence yield $\left(\mathrm{F}_{\mathrm{v}}\right)$, optimum photosystem II (PSII) quantum yield (QY) and ratio of fluorescence 
Table 1. Treatments used in the experiment.

\begin{tabular}{ll}
\hline Number & \multicolumn{1}{c}{ Treatment } \\
\hline 1 & Control (distilled water) \\
2 & $\mathrm{NaCl} 6 \mathrm{dS} \mathrm{m}^{-1}$ \\
3 & $\mathrm{NaCl} 6 \mathrm{dS} \mathrm{m}^{-1}+50 \mathrm{~mL} \mathrm{~L}^{-1}$ effective microorganisms (EM) \\
4 & $\mathrm{NaCl} 6 \mathrm{dS} \mathrm{m}^{-1}+100 \mathrm{~mL} \mathrm{~L}^{-1} \mathrm{EM}$ \\
5 & $\mathrm{NaCl} 6 \mathrm{dS} \mathrm{m}^{-1}+200 \mathrm{~mL} \mathrm{~L}^{-1} \mathrm{EM}$ \\
\hline
\end{tabular}

decline (RFD) in steady state. Emission images were taken by Charge Coupled Device (CCD) camera built in FS-FI-2200 FluorCam System. At the end of the experiment, after $6 \mathrm{wk}$ when seedlings under salt treatment became yellow and dried, the whole plants including shoot and root system were weighed, then were oven dried at $60{ }^{\circ} \mathrm{C}$ for $48 \mathrm{~h}$. Plant length was also measured for each replicate, soil samples were also taken from each replicate and analyzed for chemical properties. Data were analyzed using Minitab 18 software (Minitab, State College, Pennsylvania, USA). ANOVA was conducted followed by mean separation using LSD test at 0.05 probability level, numbers were presented as averages.

\section{RESULTS AND DISCUSSION}

Data revealed that $\mathrm{NaCl}$ application significantly reduced plant fresh and dry weight as well as plant height (Table 2). Application of EM significantly improved plant height and plant fresh and dry weights under $\mathrm{NaCl}$ treatment. However, higher levels of EM1 limited plant growth, which may be due to microbes consuming nutrients for their own survival. The other two concentrations of EM1 (50 and $100 \mathrm{~mL} \mathrm{~L}^{-1}$ ) had a substantial positive impact on all measured growth parameters and were not significantly different from the control (Table 2).

Salt inhibited plant growth and interfered with important cellular processes, leading to reduction in biomass. One of the possible factors of the inhibitory effect of salts on plant dry weight is that salt leads to nutrient imbalance and increase ion-deficiency, which decreases the plant ability to take up water and nutrient (Deinlein et al., 2014). Fresh weight was increased with bacterial inoculations. This increase reflects that bacteria can play an important role in improving wheat ability to uptake $\mathrm{Na}^{+}$from soil, making water more available to plants or increasing the water status of plants (Afrasayab et al., 2010). According to Talaat (2015) and Mtolera and Dongli (2018), EM application reduced the negative effects of salinity, which is in agreement with our results, where both fresh and dry weight were reduced with salt application, the EM application to the salt treated plants showed same results as the control. Similar results were reported by other researchers (Egamberdieva and Kucharova, 2009; Bui, 2013; Safari et al., 2016; Li and Jiang, 2017). Application of EM induced salt stress tolerance through enhancing induced systemic tolerance, which involves different physiological and biochemical changes including modulation of plant hormonal levels (Evelin et al., 2009; Girgis and Abdel-Rassoul, 2011; Belimov et al., 2015; Cohen et al., 2015; Pourbabaee et al., 2016), osmotic regulation (Armada et al., 2014), stress response genes (Kim et al., 2014) and decrease stress volatile release (Timmusk et al., 2014).

In this study, relative chlorophyll content of plant leaves was measured (Table 3). Leaf chlorophyll content was significantly $(\mathrm{P} \leq 0.01)$ reduced by $\mathrm{NaCl}$ at $6 \mathrm{dS} \mathrm{m}^{-1}$. Nonsignificant differences were observed between inoculated and non-inoculated plants (control) (39.23 SPAD units) with EM application of 100 and $200 \mathrm{~mL} \mathrm{~L}^{-1}$ (36.23 and $34.12 \mathrm{SPAD}$ units) respectively.

Table 2. Effect of effective microorganisms (EM) on plant fresh weight, dry weight and height of wheat seedlings under $\mathrm{NaCl}$ stress.

\begin{tabular}{lccc}
\hline Treatment & Plant fresh weight & Plant dry weight & Plant height \\
\hline & $\mathrm{g}$ & $\mathrm{g}$ & $\mathrm{cm}$ \\
$\mathrm{Control}$ & $1.1705 \pm 0.064 \mathrm{a}$ & $0.2372 \pm 0.0154 \mathrm{a}$ & $29.75 \pm 1.70 \mathrm{a}$ \\
$\mathrm{NaCl}$ & $0.4820 \pm 0.066 \mathrm{c}$ & $0.168 \pm 0.0209 \mathrm{~b}$ & $24.50 \pm 0.894 \mathrm{~b}$ \\
$\mathrm{NaCl}+50 \mathrm{~mL} \mathrm{~L}^{-1} \mathrm{EM}$ & $0.9212 \pm 0.074 \mathrm{ab}$ & $0.2696 \pm 0.0210 \mathrm{a}$ & $26.92 \pm 1.23 \mathrm{ab}$ \\
$\mathrm{NaCl}+100 \mathrm{~mL} \mathrm{~L}^{-1} \mathrm{EM}$ & $0.995 \pm 0.1220 \mathrm{ab}$ & $0.2773 \pm 0.035 \mathrm{a}$ & $30.00 \pm 1.06 \mathrm{a}$ \\
$\mathrm{NaCl}+200 \mathrm{~mL} \mathrm{~L}^{-1} \mathrm{EM}$ & $0.7748 \pm 0.089 \mathrm{~b}$ & $0.2210 \pm 0.0273 \mathrm{ab}$ & $25.92 \pm 1.28 \mathrm{~b}$ \\
\hline \multicolumn{4}{l}{} \\
Values are mean $\pm \mathrm{SE}(\mathrm{n}=6)$.
\end{tabular}


Table 3. Effect of effective microorganisms (EM) on chlorophyll content and photosynthesis of wheat seedlings under NaCl stress.

\begin{tabular}{lclcc}
\hline Treatment & Chlorophyll $(\mathrm{SPAD})$ & \multicolumn{1}{c}{$\mathrm{F}_{\mathrm{v}} / \mathrm{F}_{\mathrm{m}}$} & $\mathrm{QY}$ & \multicolumn{1}{c}{ RFD } \\
\hline Control & $39.23 \pm 0.94 \mathrm{a}$ & $0.6237 \pm 0.004 \mathrm{a} *$ & $0.604 \pm 0.007 \mathrm{a}$ & $0.1623 \pm 0.061 \mathrm{~b}$ \\
$\mathrm{NaCl}$ & $29.43 \pm 2.09 \mathrm{bc}$ & $0.5167 \pm 0.035 \mathrm{c}$ & $0.452 \pm 0.040 \mathrm{c}$ & $0.6750 \pm 0.153 \mathrm{a}$ \\
$\mathrm{NaCl}+50 \mathrm{~mL} \mathrm{~L}^{-1} \mathrm{EM}$ & $28.10 \pm 4.47 \mathrm{c}$ & $0.5840 \pm 0.018 \mathrm{ab}$ & $0.5628 \pm 0.025 \mathrm{~b}$ & $0.5180 \pm 0.130 \mathrm{ab}$ \\
$\mathrm{NaCl}+100 \mathrm{~mL} \mathrm{~L}^{-1} \mathrm{EM}$ & $36.23 \pm 1.44 \mathrm{ab}$ & $0.5473 \pm 0.019 \mathrm{bc}$ & $0.5127 \pm 0.023 \mathrm{bc}$ & $0.6290 \pm 0.170 \mathrm{a}$ \\
$\mathrm{NaCl}+200 \mathrm{~mL} \mathrm{~L}^{-1} \mathrm{EM}$ & $34.12 \pm 1.89 \mathrm{abc}$ & $0.5850 \pm 0.009 \mathrm{bc}$ & $0.5647 \pm 0.015 \mathrm{ab}$ & $0.4657 \pm 0.096 \mathrm{ab}$ \\
\hline
\end{tabular}

Values are mean \pm SE $(n=6)$.

Means per columns with same letter are not significantly different according to LSD test $(\mathrm{P}=0.05)$.

$\mathrm{F}_{\mathrm{v}} / \mathrm{F}_{\mathrm{m}}$ : Leaf maximum quantum yield; QY: quantum yield of photosystem II; RFD: fluorescence decline ratio.

Chlorophyll content is an important physiological parameter that can be used as an indicator of plant reaction to stress. In this study, $\mathrm{NaCl}$ stress decreased chlorophyll content in wheat seedlings. Li and Jiang (2017) reported that $\mathrm{NaCl}$ stress decreased chlorophyll content in different plants, including wheat. Reduction in chlorophyll had a negative effect on photosynthesis, which leads to reduced plant fresh weight. This may be referred to the fact that higher salt concentrations inhibited synthesis of a precursor of chlorophyll, 5-aminolevulinic acid which causes reduction in chlorophyllase (Santos, 2004). Pourbabaee et al. (2016) and Bahmani et al. (2016) reported enhanced chlorophyll content in wheat grown under saline conditions and inoculated with halotolerant bacterial strain of Bacillus mojavensis.

A reduction of $26 \%$ in chlorophyll content was observed at $6 \mathrm{dS} \mathrm{m}^{-1}$. The photosynthetic activities of plants grown under salt stress could be reduced by the effect of $\mathrm{NaCl}$ decrease. EM significantly improved photosynthetic pigments of plants (Li et al., 2020).

Data of photosynthetic activities (chlorophyll fluorescence) are presented in Table 3 . The results showed significant reduction of the quantum yield of dark adopted leaves $\left(\mathrm{F}_{\mathrm{v}} / \mathrm{F}_{\mathrm{m}}\right)$, and the quantum yield of photosystem II (QY) from light adopted leaves of wheat plants under salinity condition, however, when EM was supplemented with salt treatment, $\mathrm{F}_{\mathrm{v}} / \mathrm{F}_{\mathrm{m}}$ was increased similar to the control for the salt $+50 \mathrm{~mL} \mathrm{~L}^{-1} \mathrm{EM}$ treatment, the lowest QY value was recorded with salt treatment, the highest was in the control, but without significant difference from salt +200 EM treatment. For RFD the value was higher with salt treatment and differed significantly from the control. In general, data on photosynthesis variables revealed that there was nonsignificant difference between inoculated and non-inoculated plants, however, plants treated with $50 \mathrm{~mL} \mathrm{~L}^{-1} \mathrm{EM}$ showed a slight significant reduction in chlorophyll content, this was in line with results of Adhikari et al. (2019). These results indicated the positive effect of applying EM and by counterpart the negative effect of salt on photosynthetic activities.

Photosynthesis is a significant variable used to evaluate plant tolerance to abiotic stress. High correlation was observed between plant growth and photosynthetic rate in many plants including wheat (Maxwell and Johnson, 2000). Chlorophyll fluorescence is a quick and non-intense method used in plants screening for salinity tolerance. This study reported significant reduction in photosynthesis activities under $\mathrm{NaCl}$ treatments. Saline conditions reduced photosynthesis and as a consequence growth and productivity were reduced (Abdeshahian et al., 2010).

Leaf maximum quantum yield $\left(\mathrm{F}_{\mathrm{v}} / \mathrm{F}_{\mathrm{m}}\right)$ is the most important chlorophyll fluorescence parameter that results in an intense reduction under stress conditions (Kanwal et al., 2011). Lower $F_{v} / F_{m}$ under salt stress conditions enhance the regeneration of ribulose-1,5-bisphosphate (RuBP), which needs adequate electron translocation from PSII to electron acceptor, might be disturbed by salinity $\mathrm{F}_{\mathrm{v}} / \mathrm{F}_{\mathrm{m}}$, which was reduced under saline condition in different wheat cultivars (Kafi, 2009). Based on the measured chlorophyll fluorescence parameters, salinity negatively affected photosynthesis efficiency in Arabidopsis. In addition, applying EM enhanced plant ability to tolerate the induced salinity stress. Effective microorganisms concentration of $10 \mathrm{~mL} \mathrm{~L}^{-1}$ resulted in the best results (Kalaji et al., 2016), our result also indicated a counteracting effect of salt stress in wheat.

The EC and pH values from soil samples of different treatments are shown in Table 4. EC increased significantly when $\mathrm{NaCl}$ was added, with the highest $\mathrm{EC}$ value obtained with salt treatment only $\left(14.34 \mathrm{dS} \mathrm{m}^{-1}\right)$, however, the addition of the EM reduced the EC value $\left(10.29 \mathrm{dS} \mathrm{m}^{-1}\right)$ with a significant reduction at the higher EM level ( $\left.200 \mathrm{~mL} \mathrm{~L}^{-1}\right)$. According to the EM's manufacture manual, the high concentration of EM may cause more nutrient consumption in the media, lowering EC, such assertion agreed with Mouhamad et al. (2017) findings. The pH value was the same for all treatments. 
Table 4. Effect of $\mathrm{NaCl}$ and effective microorganisms (EM) on electrical conductivity and pH of soil media.

\begin{tabular}{lcc}
\hline Treatment & Electrical conductivity & $\mathrm{pH}$ \\
\hline & \multicolumn{1}{c}{$\mathrm{dS} \mathrm{m}^{-1}$} & \\
$\mathrm{Control}$ & $2.435 \pm 0.882 \mathrm{c}$ & $7.432 \pm 0.0822 \mathrm{a}$ \\
$\mathrm{NaCl}$ & $14.355 \pm 0.0952 \mathrm{a}$ & $7.467 \pm 0.112 \mathrm{a}$ \\
$\mathrm{NaCl}+50 \mathrm{~mL} \mathrm{~L}^{-1} \mathrm{EM}$ & $12.520 \pm 0.952 \mathrm{ab}$ & $7.480 \pm 0.106 \mathrm{a}$ \\
$\mathrm{NaCl}+100 \mathrm{~mL} \mathrm{~L}^{-1} \mathrm{EM}$ & $12.055 \pm 0.738 \mathrm{ab}$ & $7.457 \pm 0.097 \mathrm{a}$ \\
$\mathrm{NaCl}+200 \mathrm{~mL} \mathrm{~L}^{-1} \mathrm{EM}$ & $10.290 \pm 0.972 \mathrm{~b}$ & $7.510 \pm 0.093 \mathrm{a}$ \\
\hline Values are mean $\pm \mathrm{SE}(\mathrm{n}=6)$. &
\end{tabular}

Our finding was in agreement with Mtolera and Dongli (2018), who found that the application of EM reduced EC of the drained solutes. It has been reported that EM technology had positive effect on crop quality and at the same time has great potential to improve soil chemical and physical properties (Hu and Qi, 2013; Talaat, 2015; Mtolera and Dongli, 2018). In our experiment, the effect of EM application on soil $\mathrm{pH}$ was not clear, however, in a long term experiment of $11 \mathrm{yr}(\mathrm{Hu}$ and Qi, 2013; Belimov et al., 2015) reported significant reduction on soil pH from 7.53 to 7.15 with EM application. Soil $\mathrm{pH}$ adjustment result in increasing availability of nutrients for plant growth.

\section{CONCLUSIONS}

This work advocates that effective microorganisms (EM) application for wheat under $\mathrm{NaCl}$ stress condition can alleviate the $\mathrm{NaCl}$ stress effect. In addition, it showed that chlorophyll fluorescence yield, and quantum efficiency of photosystem II are reliable indicators of tolerance to salinity stress in wheat plants and that EM can reduce its impact. Therefore, EM can be used to enhance production of wheat grown in salinity-affected areas, however, more investigations are needed with different inoculations protocols and more wheat varieties.

\section{REFERENCES}

Abdeshahian, M., Nabipour, M., and Meskarbashee, M. 2010. Chlorophyll fluorescence as criterion for the diagnosis salt stress in wheat (Triticum aestivum) plants. International Journal of Nuclear and Quantum Engineering 4(11):839-841.

Adhikari, N.D., Simko, I., and Mou, B. 2019. Phenomic and physiological analysis of salinity effects on lettuce. Sensors 19(21):4814.

Afrasayab, S., Faisal, M., and Hasnain, S. 2010. Comparative study of wild and transformed salt tolerant bacterial strains on Triticum aestivum growth under salt stress. Brazilian Journal of Microbiology 41(4):946-955.

Armada, E., Roldán, A., and Azcon, R. 2014. Differential activity of autochthonous bacteria in controlling drought stress in native Lavandula and Salvia plants species under drought conditions in natural arid soil. Microbial Ecology 67(2):410-420.

Ashraf, M., Hasnain, S., Berge, O., and Mahmood, T. 2004. Inoculating wheat seedlings with exopolysaccharide-producing bacteria restricts sodium uptake and stimulates plant growth under salt stress. Biology and Fertility of Soils 40(3):157-162.

Bahmani, M., Jalali, G.A., Asgharzadeh, A., and Tabari Kouchaksaraei, M. 2016. Effect of inoculation growth promotion bacterium Pseudomonas putida on tolerance to salinity of Calotropis procera Ait. seedlings. Arid Biom Scientific and Research Journal 6(1):81-94.

Belimov, A.A., Dodd, I.C., Safronova, V.I., Shaposhnikov, A.I., Azarova, T.S., Makarova, N.M., et al. 2015. Rhizobacteria that produce auxins and contain 1-amino-cyclopropane-1-carboxylic acid deaminase decrease amino acid concentrations in the rhizosphere and improve growth and yield of well-watered and water-limited potato (Solanum tuberosum). Annals of Applied Biology 167(1):11-25.

Bui, E. 2013. Soil salinity: A neglected factor in plant ecology and biogeography. Journal of Arid Environments 92:14-25.

Cohen, A.C., Bottini, R., Pontin, M., Berli, F.J., Moreno, D., Boccanlandro, H., et al. 2015. Azospirillum brasilense ameliorates the response of Arabidopsis thaliana to drought mainly via enhancement of ABA levels. Physiologia Plantarum 153(1):79-90.

Deinlein, U., Stephan, A.B., Horie, T., Luo, W., Xu, G., and Schroeder, J.I. 2014. Plant salt-tolerance mechanisms. Trends in Plant Science 19(6):371-379.

Egamberdieva, D., and Kucharova, Z. 2009. Selection for root colonizing bacteria stimulating wheat growth in saline soils. Biology and Fertility of Soils 45(6):563-571. 
Evelin, H., Kapoor, R., and Giri, B. 2009. Arbuscular mycorrhizal fungi in alleviation of salt stress: A review. Annals of Botany 104(7):1263-1280.

Girgis, M., and Abdel-Rassoul, M 2011. Enhanced salt tolerance of wheat plant. Environmental Science 6(4):31-52.

Hasegawa, P.M., Bressan, R.A., Zhu, J.K., and Bohnert, H.J. 2000. Plant cellular and molecular responses to high salinity. Annual Review of Plant Biology 51(1):463-499.

Hu, C., and Qi, Y. 2013. Long-term effective microorganisms application promote growth and increase yields and nutrition of wheat in China. European Journal of Agronomy 46:63-67.

Kafi, M. 2009. Effect of salinity and light on photosynthesis respiration and chlorophyll fluorescence in salt-sensitive wheat (Triticum aestivum) cultivars. Journal of Agriculture, Science and Technology 11:547-555.

Kalaji, H.M., Cetner, M.D., Samborska, I.A., Lukasik, I., Oukarroum, A., Rusinowski, S., et al. 2016. Effective microorganisms impact on photosynthetic activity of Arabidopsis plant grown under salinity stress conditions. Annals of Warsaw University of Life Sciences-SGGW, Land Reclamation 48(2):153-163.

Kanwal, H., Ashraf, M., and Shahbaz, M. 2011. Assessment of salt tolerance of some newly developed and candidate wheat (Triticum aestivum L.) cultivars using gas exchange and chlorophyll fluorescence attributes. Pakistan Journal of Botany 43(6):2693-2699.

Kaushal, M., and Wani, S.P. 2016. Rhizobacterial-plant interactions: strategies ensuring plant growth promotion under drought and salinity stress. Agriculture, Ecosystems and Environment 231:68-78.

Kim, K., Jang, Y.J., Lee, S.M., Oh, B.T., Chae, J.C., and Lee, K.J. 2014. Alleviation of salt stress by Enterobacter sp. EJ01 in tomato and Arabidopsis is accompanied by up-regulation of conserved salinity responsive factors in plants. Molecules and Cells 37(2):109.

Li, H., and Jiang, X. 2017. Inoculation with plant growth-promoting bacteria (PGPB) improves salt tolerance of maize seedling. Russian Journal of Plant Physiology 64(2):235-241.

Li, X., Shao, X., Ding, F., Yuan, Y., Li, R., Yang, X., et al. 2020. Effects of effective microorganisms biochar-based fertilizer on photosynthetic characteristics and chlorophyll content of flue-cured tobacco under water-saving irrigation strategies. Chilean Journal of Agricultural Research 80:422-432.

Long, X.H., Zhao, J., Liu, Z.P., Rengel, Z., Liu, L., Shao, H.B., et al. 2014. Applying geostatistics to determine the soil quality improvement by Jerusalem artichoke in coastal saline zone. Ecological Engineering 70:319-326.

Maxwell, K., and Johnson, G.N. 2000. Chlorophyll fluorescence-a practical guide. Journal of Experimental Botany 51(345):659-668.

Mouhamad, R.S., Mutlag, L.A., Al-Khateeb, M.T., Iqbal, M., Nazir, A., Ibrahim, K.M., et al. 2017. Reducing water salinity using effective microorganisms. Net Journal of Agricultural Science 5(3):114-120.

Mtolera, I., and Dongli, S. 2018. Effect of effective microorganism and gypsum amendments on nutrient leaching, pH, electrical conductivity, and okra growth parameters under coastal saline soil. Communications in Soil Science and Plant Analysis 49(18):2327-2337.

Pourbabaee,A.A., Bahmani, E., Alikhani, H.A., and Emami, S. 2016. Promotion of wheat growth under salt stress by halotolerant bacteria containing ACC deaminase. Journal of Agriculture and Technology 18(1):855-864.

Safari, D., Jamali, F., Nooryazdan, H.R., and Bayat, F. 2016. Screening fluorescent pseudomonads isolated from wheat rhizosphere for plant growth-promoting and salt tolerance properties. Biological Forum - An International Journal 8(1):35-42.

Santos, C.V. 2004. Regulation of chlorophyll biosynthesis and degradation by salt stress in sunflower leaves. Scientia Horticulturae 103(1):93-99.

Singh, R.P., and Jha, P.N. 2016. The multifarious PGPR Serratia marcescens CDP-13 augments induced systemic resistance and enhanced salinity tolerance of wheat (Triticum aestivum L.) PLOS ONE 11(6):e0155026.

Sun, H., Lu, H., Chu, L., Shao, H., and Shi, W. 2017. Biochar applied with appropriate rates can reduce N leaching, keep N retention and not increase $\mathrm{NH}_{3}$ volatilization in a coastal saline soil. Science of the Total Environment 575:820-825.

Talaat, N.B. 2015. Effective microorganisms modify protein and polyamine pools in common bean (Phaseolus vulgaris L.) plants grown under saline conditions. Scientia Horticulturae 190:1-10.

Timmusk, S., Abd El-Daim, I.A., Copolovici, L., Tanilas, T., Kännaste, A., Behers, L., et al. 2014. Drought-tolerance of wheat improved by rhizosphere bacteria from harsh environments: enhanced biomass production and reduced emissions of stress volatiles. PLOS ONE 9(5):e96086.

Upadhyay, S.K., and Singh, D.P. 2015. Effect of salt-tolerant plant growth-promoting rhizobacteria on wheat plants and soil health in a saline environment. Plant Biology 17(1):288-293.

Xu, N., Tan, G., Wang, H., and Gai, X. 2016. Effect of biochar additions to soil on nitrogen leaching, microbial biomass and bacterial community structure. European Journal of Soil Biology 74:1-8. 